دراسة مقارنة لتأثير تمارين الاثقال والاستثفاء بين القسمين العلوي والسفلي من الجسم وتمرين مختلط بينهما في هرمون النمو - التود

$$
\begin{aligned}
& \text { دراسة هقارنة لتأثير تمارين الاثقال والاستشفاء بين القسمين }
\end{aligned}
$$

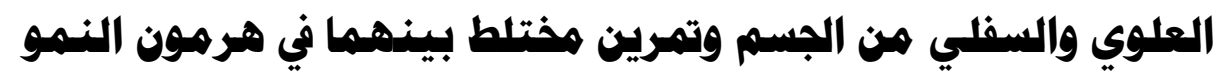

$$
\begin{aligned}
& \text { أ.د أحمد عبد الغني الدباغ هن } \\
& \text { كلية التربية البدنية وعلوم الرياضة / جامعة الموصل }
\end{aligned}
$$

Ahmed1@uomosul.edu.iq م.م. أحمد يونس حامد ملاعلو

مديرية تربية نينوى

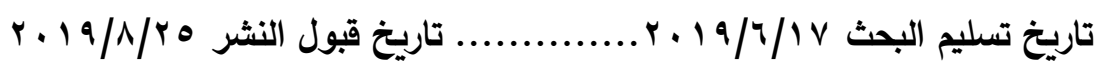

\title{
|ll|
}

الغرض من البحث هو دراسة مقارنة لتأثير حمل استنفاذي لتمارين القسم العلوي والسفلي والمختلط في تركيز هرمون

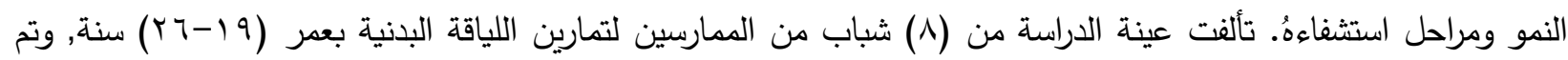
اخضاعهم لتمارين الاثقال لمدة (T) اسابيع من اجل التآلف و تفاديا للإصابات التي تحدث في الثناء تتفيذ الاختبارات الرئيسة إذ تألفت الاختبارات من ثلاثة تمارين استنفادية هي (تمارين ضغط الصدر من وضع الاستلقاء للقسم العلوي, وتمارين

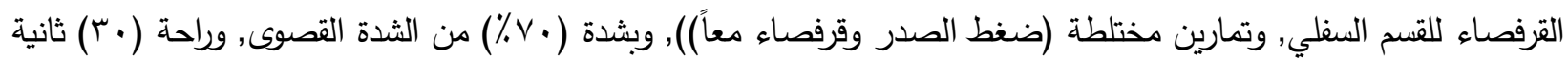

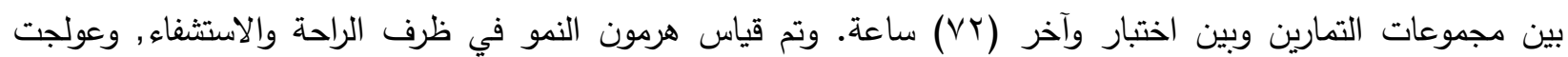

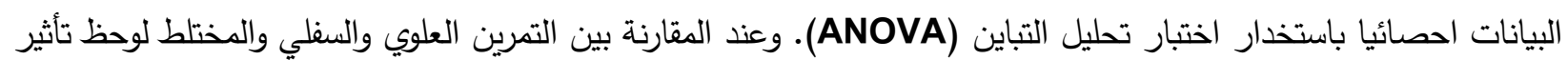
معنوي في ظروف الاستثفاء (بعد الجها , V دقائق , · r دقيقة , .r دقيقة), ولوحظ هناك تأثير معنوي في مدة الاستشفاء

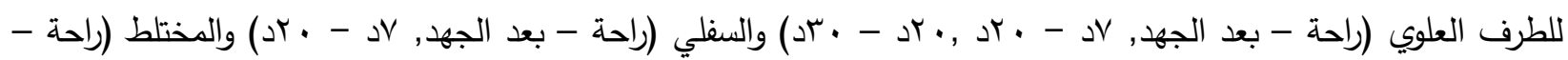

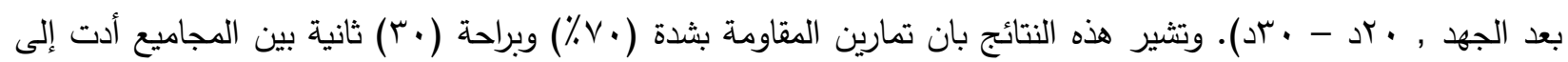
تأثير معنوي لمتغيرات الدراسة في التمرين المختلط أكثر من تمارين القسم العلوي والسفلي, وبين تمارين القسم السفلي أكثر من تمارين القسم العلوي. وبالختام أوصى البحث بالأخذ بنظر الاعتبار مدة الراحة بين الوحدات التدريبية عند التدريب باستخدام

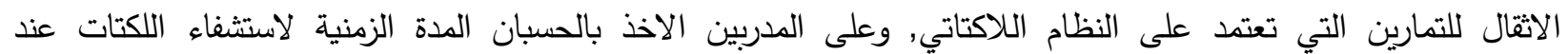
المنافسات التي تعتمد على النظام اللاكتاتي كنظام سائد.

$$
\text { الكلمات المفتاحية: (تمارين المقاومة, الاستثفاء , لاكتات الدم). }
$$

\section{Comparative Study of the Effect of Resistance Exercises and Recovery between the Upper and Lower Parts of the Body and a Mixed exercise between them in Growth Hormone}

$\begin{array}{ll}\text { Prov.Dr.,Ahmed.A. Taha } & \begin{array}{l}\text { Ahmedataha@yahoo.com } \\ \text { Ahmed1@uomosul.edu.iq }\end{array} \\ \text { Ahmed.Y.Hamed } & \text { uhomol }\end{array}$

The purpose of the study is a comparative study of the effect of exhaustive load for upper and lower limb exercises and mixed exercises on stages of recovery in concentration of Growth Hormone. The sample consisted of (8) students aged (19-26) years and they were subjected to a six-week training program to avoid injuries that occurred during the implementation of the main tests. The main tests consisted of three exhaustive exercises (Bench press exercises for the upper limb), Squat exercises for the lower limb, mixed exercises (Bench press exercises and squat together)), at intensity (70\%) and rest interval between the exercise groups consisted of (30) seconds for all exercises, and between the test and the last (72) hours. The growth hormone were measured at rest and recovery, data were processed statistically treated by using (ANOVA) test. 
When comparing the upper, lower, and mixed exercise, a significant effect was observed in the condition (post-effort, $7 \mathrm{~min}, 20 \mathrm{~min}, 30 \mathrm{~min}$ ), a significant effect was observed in the recovery conditions (post-effort, $7 \mathrm{~min}, 20 \mathrm{~min}, 30 \mathrm{~min}$ ), and significant effect was observed in the Recovery conditions for upper limbs (Rest-post-effort, $7 \mathrm{~min}-20 \mathrm{~min}, 20 \mathrm{~min}-30 \mathrm{~min}$ ), The lower limbs (rest-post-effort, $7 \mathrm{~min}-20 \mathrm{~min}$ ) and mixed exercise ((rest-post-effort, $20 \mathrm{~min}-30 \mathrm{~min}$ )). These results indicate that the resistance exercises at intensity (70\%) and rest (30) seconds between the groups resulted in a significant effect of the study variables in the mixed exercise more than the exercises of the upper and lower limbs, and lower limbs exercises more than the exercises of the upper limbs. In conclusion, study had recommended considering the period of rest between the training modules when training using weights for exercises that based on the lactate system. trainers should take into account the periods of recovery in the competitions that rely on the lactate system as a common system.

Key Words: (Resistance exercises, Recovery, Lactate).

\section{1-التعريف بالبحث: 1- 1- 1 المقدمة واهمية البحث:}

يعد هرمون النمو من المتغيرات المهمة التي تؤخذ بالحسبان عند وضـع واعداد التمرينات والبرامج التدربية التي لهم علاقة بالنظم اللاهوائية. ولكن يبقى السؤال أيهما أكثر إثارة لهذا الهرمون المجاميع العضلية في القسم العلوي أم السفلي في الجسم أم كلاهما, اذا علمنا بوجود اختلاف في تركيبة هذه المجاميع من ناحية المقطع العرضي, وتوزيع نسب الالياف العضلية, والامداد العصبي وتوزيع الدم وغيرها. هذا ومن ناحية أخرى يوجد اعتقاد في الوقت الحالي لاى مدربي اللياقة البدنية في قاعات الاتقال يذهب الى ارتباط صفة القوة بهرون النمو الذي يؤثر في حرق السعرات الحراريـة وبناء القوة العضلية. إذ توصلت دراسـة (Madarame etal, 2010) مقارنة استجابات الغدد الصماء عند ممارسة تمـارين المقاومـة بشدد منخفضـة مـع تقييد تدفق الدم لعضـلات القسم العلوي والقسم السفلي وتوصلت الدراسة

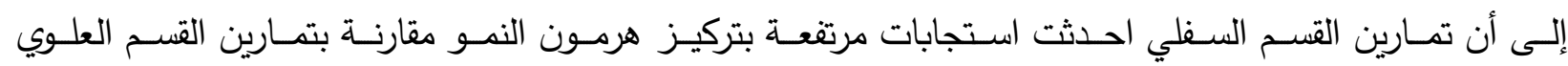
(Madarame etal, 2010, 192), ودراسة (Häkkinen etal 1998) كانت حول الاستجابات الهرمونية الحادة لتمـارين المقاومـة الثابتـة وبشـدة مرتفعـة للقسـم العلوي والسفلي والمختلط لدى شباب و المسنين الرجـال, وتوصـلت

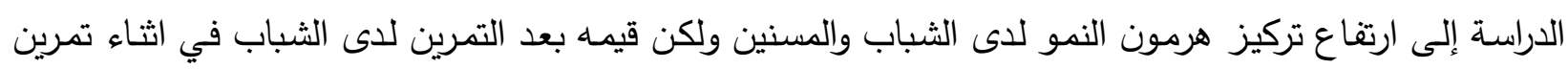
القسم السفلي كان أكثر عند مقارنته بالمسنين. (Häkkinen etal, 312, 1998). ومن هنا تتضـح اهمية الدراسة الحالية في استجابة هرمون النمو بعد تمرين ذو حمل استنفاذي باستخدام الاثقال في كل من القسمين العلوي والسفلي من الجسم وتمرين مختلط بينهما, وهذه المتغيرات في فترات استعادة شفاء سلبية متتوعة اعتمادا على ازمنة استثفاء تدريبية كلاسيكية وحديثة, وكذلك اعتمادا على ازمنة الآليات الفسيولوجية لازمنة هرمون النمو. 1-

إن تأثير مجموعـة مـن المتغيـرات المستقلة(نوع التمـرين: في القسـم العلوي أو السـفلي أومختلط)وكميـة الكتلـة العضلية المستخدمة في تمارين هذه الأقسام في هرمون النمو،ثم تتبعه في مراحل استثفاء مختلفة منها ذات ازمنة تدريبية وآخرى وفقا لماتحدده الآليات الفسيولجية لاستشفاء هرمون النمو قيد الدراسة ويمكن طرح مشكلة البحث ضمن هرن التساؤلات الآتية:

- - اي حمل تدريبي باستخدام الاتقال في القسمين العلوي والسفلي وتمرين مختلط بينهما يثير اقصى تركيز لهرمون النمو قيد الدراسة؟ 


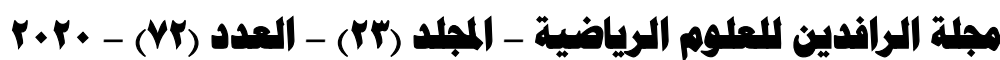

دراسة مقارنة لتأثير تمارين الاثقال والاستثفاء بين القسمين العلوي والسفلي من الجسم وتمرين مختلط بينهما في هرمون النمو

- - وما مقدار الزمن اللازم لاستثفاء هرمون النمو ضمن المفاهيم التدريبية والفسلجية؟

$$
\text { r-1 }
$$

- - المقارنة بين تاثير حمل استنفاذي بالأتقال في القسم العلوي مع القسم السفلي من الجسم وتمرين مختلط بينهما في اقصى تراكم لهرمون النمو.

- - المقارنة بين استعادة شفاء هرمون النمو بعد حمل استنفاذي بالأثقال للقسم العلوي مع القسم السفلي من الجسم

وتمرين مختلط بينهما.

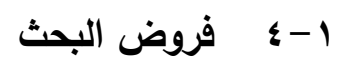

- عدم وجود فروق ذات دلالة معنوية لتأثير حمل استنفاذي بالاثقال في القسم العلوي مع القسم السفلي من الجسم وتمرين مختلط بينهما في اقصى تركيز لهرمون النمو.

- عدم وجود فروق ذات دلالة معنوية بين استعادة شفاء هرمون النمو بعد حمل استنفاذي بالاثقال للقسم العلوي مع القسم السفلي من الجسم وتمرين مختلط بينهما.

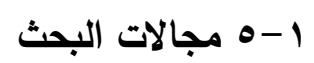

1-0-1 المجال البشري:عينة من ذوي الصحة الجيدة الممارسين للنشاط البدني.

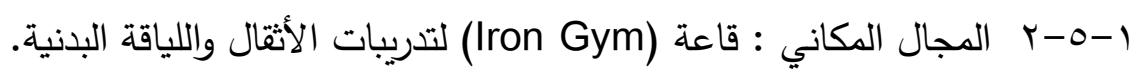

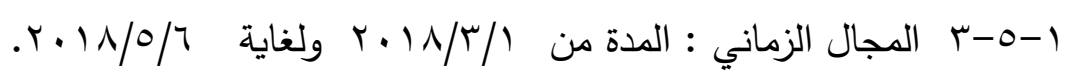

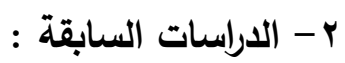

(Häkkinen etal 1998) (19) "الاستجابات الهرمونية الحادة لتمارين المقاومة الثابتة وبشدة مرتفعة للقسم العلوي والسفلي والمختلط لاى شباب

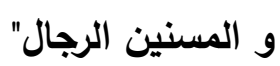
كان الغرض من الدراسة هو معرفة الاستجابات الهرمونية (هرمون النمو, والتستوستيرون, والتستوستيرون الحر (TT \& FT) (الكورتزول) واللكتات لتمارين المقاومة الثابتة وبشدة مرتفعة للقسم العلوي والسفلي والمختلط. اذ تكونت (T)

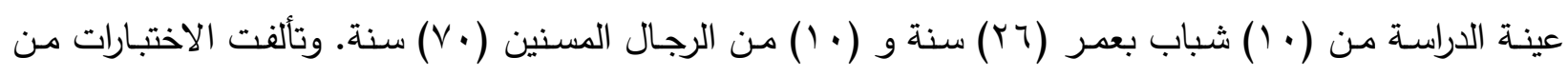
ثلاثة تمارين, تمرين للقسم العلوي (بنج برس بذراع واحدة), وتمرين القسم السفلي (مد الركبة), وتمرين مختلط (تمرين

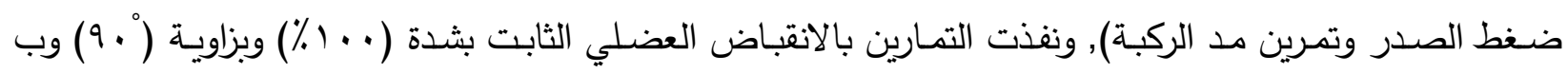
(• ( تكرارات) وبزمن (0 ثوانٍ) لكل تكرار مـع راحة لمدة (0 ثوانٍ) بين التكرارات, وكان عدد المجاميع (ع) وكان

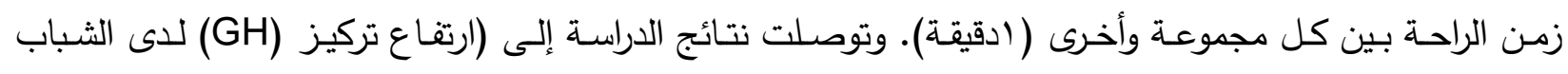
والمسنين ولكن قيمه بعد التمرين لدى الثباب في اثناء تمرين القسم السفلي كان اكثر عند مقارنته ب بالمسنين, كما ارتفع تركيز هرمون التستوستيرون (TT) لدى الثباب في كل التمارين الثلاثة, بينما في المسنين فان هذه الزيـادة ظهرت فقط في تمرين القسم السفلي, وارتفع تركيز هرمون والتستوستيرون الحر (FT) لدى الثباب في تمرين القسم السفلي والمختلط, وظهرت في التمرين المختلط فقط بالنسبة للمسنين, ولوحظ زيادة كبيرة قبل وبعد التمرين في (FT) لدى الثباب مقارنة بالمسنين, بينما لم يظهر ارتفاع معنوي في هرمون الكورتزول لدى الفئتين في التمارين الثلاثة, 


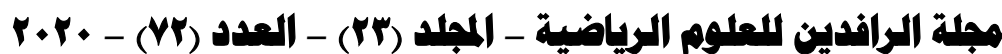

دراسة مقارنة لتأثير تمارين الاثقال والاستشفاء بين القسمين العلوي والسفلي من الجسم وتمرين مختلط بينهما في هرمون النمو

وكذلك ارتفع تركيز اللكتات في اثناء التمارين ولكلا الفئتين ولكن قيمه بعد تمرين القسم السفلي والمختلط في الثباب

$$
\text { كان أعظم من المسنين). }
$$

r - التعليق على الدراسة السابقة

عند اجراء تحليل للدراسة السابقة توصلنا إلى ما يأتي:

ا. ـ قارنت الدراسة السابقة بين القسمين العلوي والسفلي والمختلط وكان غرض الدراسة من اجل مقارنة الاستجابات

$$
\text { الهرمونية بين الثباب والمسنين. }
$$

r. استخدمت هذه دراسة (Häkkinen etal 1998) الانقباض العضلي الثابت بثدة ( . . 1\%) للمقارنة بين القسمين العلوي والسفلي بينما الدراسة الحالية استخدمت الحمل الاستفاذي بالانقباض العضلي المتحرك (المركزي واللامركزي) وبشدة ( • (\%).

r. لم تتطرق دراسة (Häkkinen etal 1998) إلى دراسة مراحل الاستثفاء.

$$
\text { r- اجراءات البحث }
$$

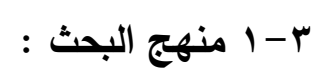

تم استخدام المنهج الوصفي بوصفه المنهج المناسب للوصول إلى أهداف البحث

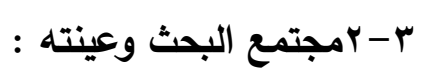

بعد أن حدد الباحث مجتمع البحث المتكونة من الثباب بأعمار (9 (19 r) سنة, تم اختيار عينة البحث بصورة

\begin{tabular}{|c|c|c|c|c|c|}
\hline \multirow{2}{*}{ الاختلاف معامل } & \multicolumn{2}{|c|}{ العينة } & \multirow{2}{*}{ القياس } & \multirow[t]{2}{*}{ المعالم الإحصائية } & \multirow[b]{2}{*}{ المتغيرات } \\
\hline & $\varepsilon \pm$ & سَ & & & \\
\hline$\%$ r. . V & ๕.7. & IVY & سم & الطول & \multirow{5}{*}{ المواصفات } \\
\hline$\%$ & V. Tr & VI. & كفم & الوزن & \\
\hline$\% \wedge . \neg \wedge$ & 1.91 & Yr.AO & سنة & العمر & \\
\hline$\% \wedge . \leqslant 9$ & r.. & $r \leq . r \leq$ & كغم / م & مؤشر كتلة الجسم & \\
\hline$\% 0.1 \leq$ & r.Ir & $7.7 \varepsilon$ & $\%$ & نسبة الكتلة & \\
\hline
\end{tabular}

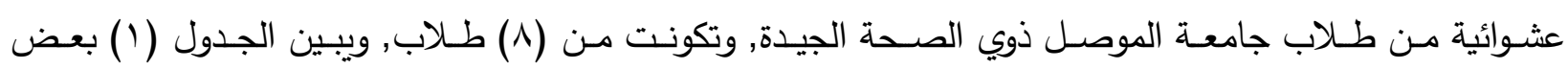
مواصفات عينة البحث.

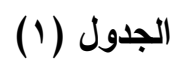

يبين مواصفات عينة البحث

يتبين من الجدول السابق تجانس العينة في المتغيرات (الطول, والعمر , والوزن), إذ كانت قيم معامل الاختلاف

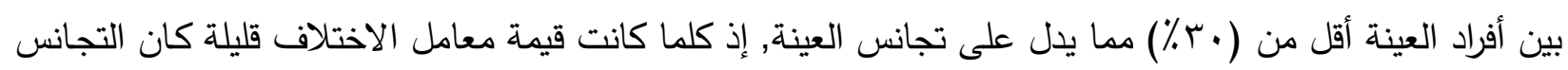
بين العينة في المتغيرات المذكورة أنفاً كبيرة. 


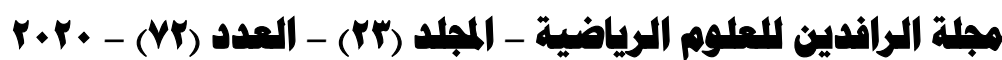

دراسة مقارنة لتأثير تمارين الاثقال والاستثفاء بين القسمين العلوي والسفلي من الجسم وتمرين مختلط بينهما في هرمون النمو

r-r الأجهزة والأدوات المستخدمة:

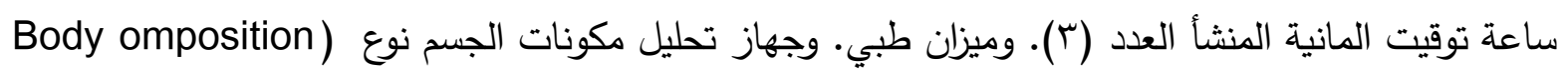
(BC - 418 MA) (Analyzer

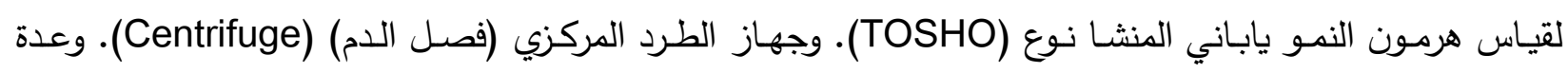

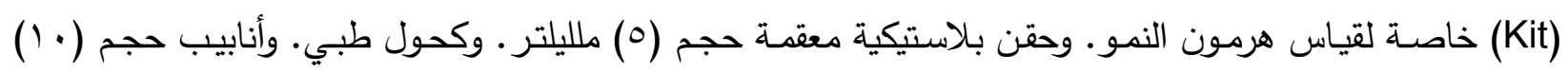
مليلتر لفصل الدم داخل جهاز فصل الدم • وقناني حاويـة على مانع تخثر (Gel Tube). وشريط ضـاغط لربط الذراع. ومسطبة مستوية. وقضيب حديد قياسي (بار معدني). وأثقال واقراص حديدية ذات اثقال مختلفة. ولوحة من الخشب بطول (1) متر (مقياس الرسم). r- بـ وسائل جمع البيانات:

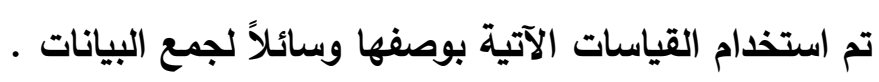
ب- ب- - القياسات الجسمية r-ع - 1- إياس طول الجسم (سم) ووزنه (كفم) إذ تم قياس الطول لأفراد عينـة البحث بجهاز قياس الطول والوزن نوع (Detecto) أمريكي المنشأ، إذ يقف المختبر على قاعدة الجهاز حافي القدمين وباستقامة القائم المعدني المثبت بشكل عمودي على الجهاز، بعدها يقوم الثخص الذي يقوم بالقياس بإنزال المسطرة المعدنية الصغيرة بحيث تلامس أعلى رأس المختبر بالسنتيمتر ، كما تم

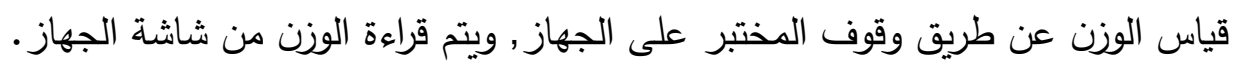

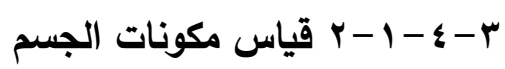

يتم قياس مكونات الجسم لعينـة البحث باستخدام جهاز تحليل مكونات الجسم نوع Body Composition (Analyzer) (BC - 418 MA الاحتياطات الآتية :- الذهاب لدورة المياه قبل الاختبار بنصف سـاعة. والذهاب لدورة المياه قبل الاختبار • وعدم التدريب لمدة (ع r) ساعة قبل بدء الاختبار • وعدم تتاول الطعام أو السوائل قبل (؟) ساعات من الاختبار • وازالة الملابس (عدا الملابس الداخلية ) والحذاء أو أي قطعة معدنية خاتم - سـاعة. ثم غسل اليدين والقدمين وتجفيفهـا من الماء قبل الاختبار على جهاز تحليل مكونات الجسم. يتكون الجهاز من ثلاثة أجزاء هي ( قاعدة الجهاز اذ يوجد في أعلاها قطعتين من المعدن لوضـع القدمين عليها في اثثاء القياس ، لذلك يطلق عليها (Foot to Foot), قائم يصل بين لوحة المعلومات, وقاعدة الجهاز , ولوحة الجهاز اذ تشمل على معلومات تتعلق بـ ( الجنس، والعمر، وكتلة الملابس (كغم ), والطول(سم)، وطابعة لنتائج القياسات المذكورة, وصلة تيار كهربائي). و تمت خطوات القياس وفق ما يأتي:

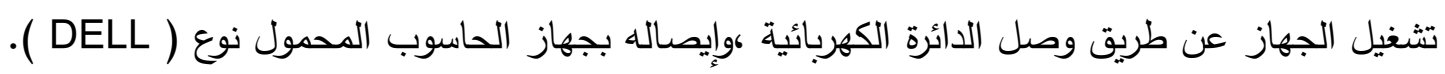
تزويد الجهاز بالمعلومات وهي ( الجنس، والعمر بالثهر وبالسنة، وكتلة الملابس, والطول (سم)). ثم ينتظر المختبر لحين أعطاء الجهاز إشارة (Stand on) للصعود على الجهاز • ويقف المختبر قدميه على القطعتين المعدنيتين, ثم يحمل المختبر المقبضين المثبتين على لوحـة الجهاز , ويقوم الجهاز بالعمل على أجراء التحليل لمدة (•r) ثانيـة 


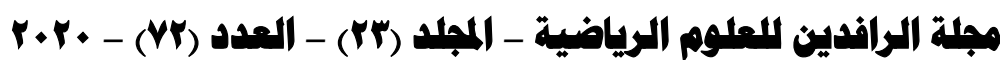

دراسة مقارنة لتأثير تمارين الاثقال والاستثفاء بين القسمين العلوي والسفلي من الجسم وتمرين مختلط بينهما في هرمون النمو

تقريباً, ويبقى المختبر واقفاً على الجهاز لحين طباعـة النتائج من قبل الجهاز الكترونياً. إن المدة الزمنية لعملية

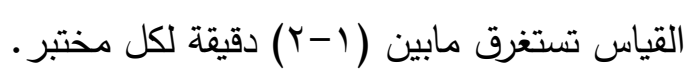

r- ب- - r- القياسات الوظيفية

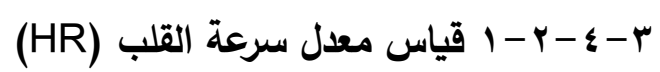

يتم قياس معدل سرعة القلب عن طريق, حزام متحس يربط حول صدر الفرد تحت مستوى حلمتي الثدي, مائلاً قليلاً إلى اليسار , إذ يرسل هذا المتحسس, موجات إلى ساعة الكترونية تحتوي على مستقبل يعمل على تحليل الإثـارة ويعطي قيمة النبض الذي يظهر على شاشة الساعة بصورة مباشرة. ب- ع-ب القياسات المختبرية r-

يتم قياس الهرمون عن طريق سحب عينة دم من الوريد ووضعاه في انبوبـة اختبار نظيفة (Blank tube), وتفصل مكونات الدم من مواد صلبة وكريات دم الحمر والبيض وصفائح دمويـة عن بقية الدم بواسطة جهاز الطرد

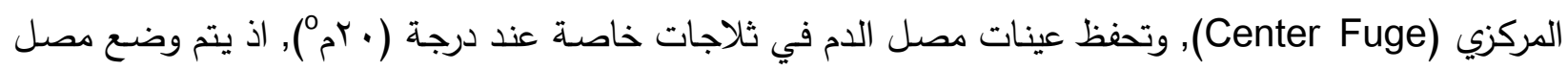

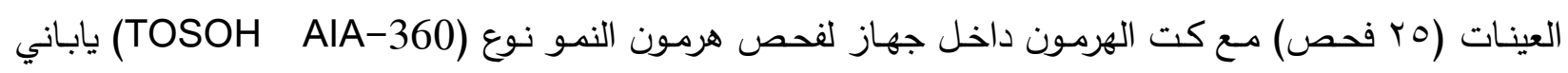
المنشأ, ويغلق الجهاز ليقوم بخلط المصل مع الهرمون أوتوماتيكياً وبعد مرور (Y0) دقيقة تقريباً, تظهر لنا النتائج بواسطة شاشة الجهاز . مان. ب-ه شرح الاختبارات البدنية r- ب- ب- التمارين الاثقال

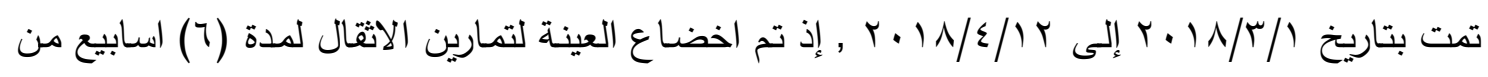
اجل التآلف والتعود على تمارين الأثقال و تفاديا للاصابات التي تحدث في اثثاء تنفيذ الاختبارات الرئيسة. r- r- التجارب الاستطلاعية r- - - - التجربة الاستطلاعية الأولى

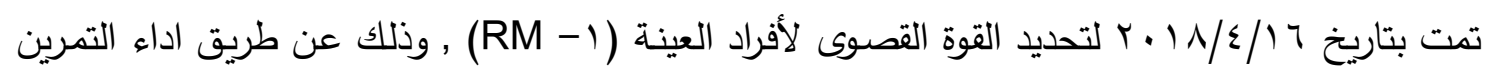
بأقصى وزن ممكن, ولمرة واحدة لتمريني ضغط الصدر (القسم العلوي), وتمرين القرفصاء (القسم السفلي). إذ نعطي

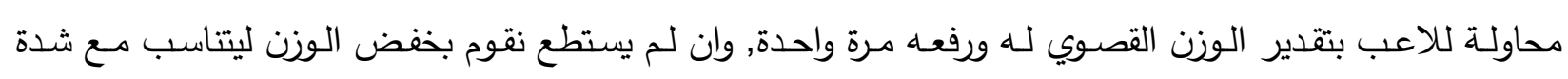

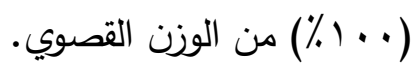

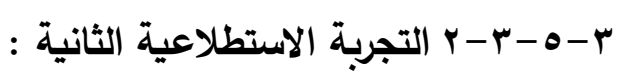

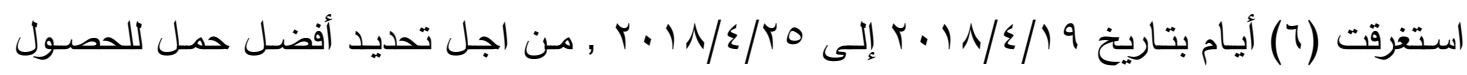
على اقصى تراكم للاكتات وذلك عن طريق قياس النبض. r- - -

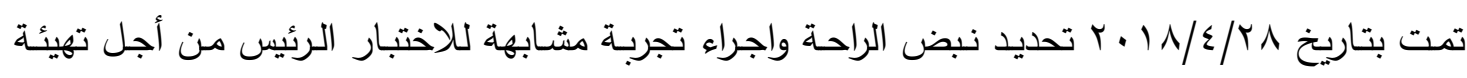
فريق العمل المساعد للاختبار الرئيس ممن سيقوم بالقياسات, والمساعدة في التجربـة تلافيا للإرباك والسلبيات التي لتي يمكن ان تحدث في التجربة الرئيسة. 


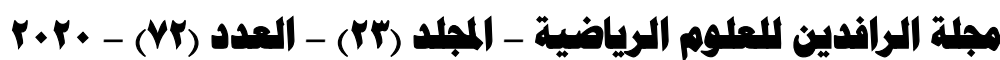

دراسة مقارنة لتأثير تمارين الاثقال والاستثفاء بين القسمين العلوي والسفلي من الجسم وتمرين مختلط بينهما في هرمون النمو

r- r- r التجربة الرئيسة

يمكن تلخيص التجربة الرئيسة بالنقاط الآتية:

ا. ـ يتم اجراء الاحماء لمدة (0) دقائق, وبعدها تعطى (Y) دقيقتان راحة سلبية وبعدها ينفذ الاختبار , اذ يتم تسجيل النبض بعد الانتهاء من كل تكرار مع ملاحظة ان فترات الراحة بين التكرارات تكون غير كاملة (•r) ثانية ويستمر اللاعب باداء التكرارات لحين الوصول إلى مرحلة إستنفاد الجهد.

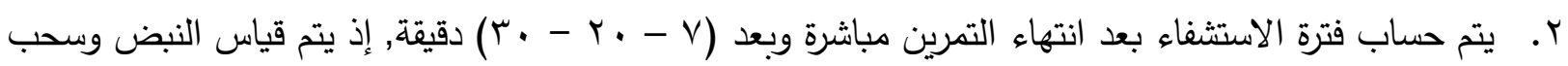
الدم في هذه الدقائق, اذ يسحب كمية (. r.0 مليلتر) من الدم لقياس هرمون النمو قيد الدراسة.

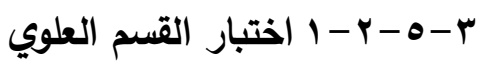

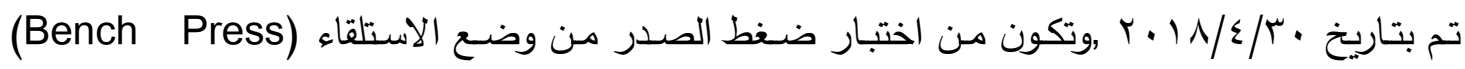
بالذراعين وبشدة (• ^\%) من اقصى شدة وبواقع (^) تكرارات للمجموعة الواحدة, ولأقصى عدد من المجموعات وبمدة راحة ( • ب) ثانية بين مجموعة وأخرى ولحين وصول الفرد لمرحلة إستنفاد الجهد. r- r- r- r- اختبار القسم السفلي

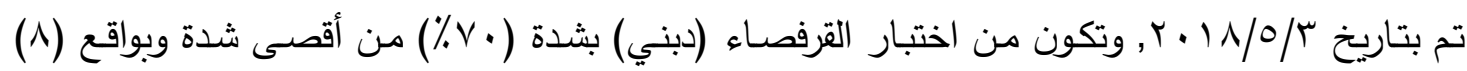

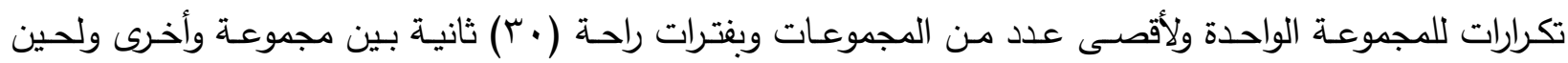
وصول الفرد لمرحلة إستنفاد الجهد.

r- r-

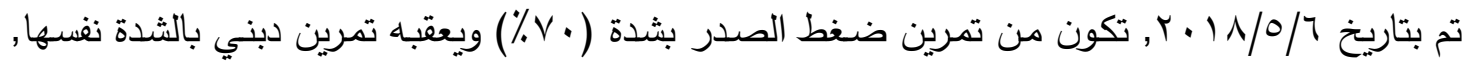

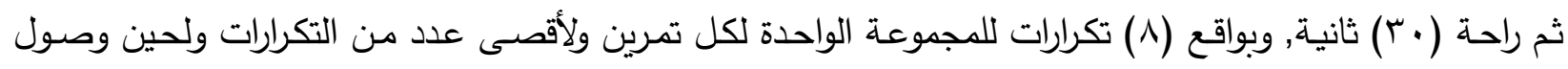
الفرد لحالة التعب.

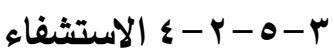

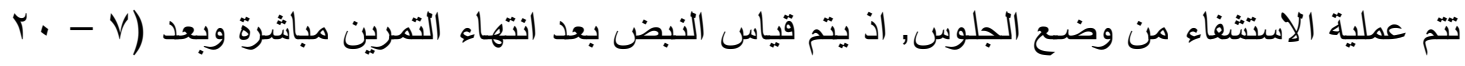

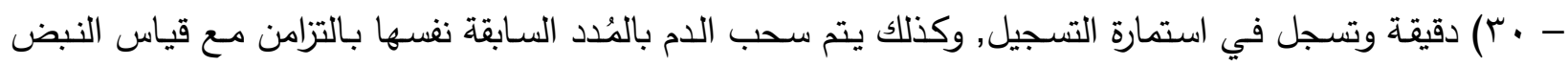
لاستخراج هرمون النمو.

r- الوسائل الإحصائية: (الوسط الحسابي (سَ), والانحراف المعياري (士 ع), ومعامل الاختلاف (خ), والنسبة المؤيسة للتغيير , وتحليل التباين, وتحليل التباين بطريقة القياسات المتكررة (Repeated Measurements) ). وتمت معالجة البيانات باستخدام

الحزمة الاحصائية (SPSS, 11.5), كما وتمت معالجة الرسوم الاحصائية باستخدام البرنامج (Excel, 2010). 


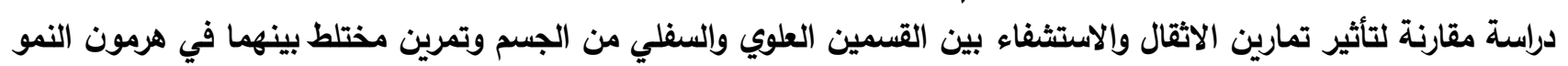

ع - عرض النتائج وتحليلها ومناقشتها: ع - 1 عرض النتائج وتحليلها ومناقشتها للمقارنة بين تاثير حمل استنفاذي بالاثقال في القسم العلوي مع القسم السفلي وتمرين مختلط بينهما في اقصى تراكم لهرمون النمو:

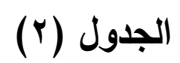

مواصفات تمارين ألقسم العلوي والسفلي

وتمرين مختلط بينهما لهرمون النمو في ظروف الراحة والاستشفاء

\begin{tabular}{|c|c|c|c|c|}
\hline$\varepsilon \pm$ & سَنَ & عدد الفراد & التمارين & ظرف الاختبار \\
\hline 0.52 & 0.75 & 8 & العلوي & \multirow{4}{*}{ الراحة } \\
\hline 0.52 & 0.75 & 8 & السفلي & \\
\hline 0.52 & 0.75 & 8 & المختلط & \\
\hline 0.50 & 0.75 & 24 & المجموع & \\
\hline 1.60 & 3.25 & 8 & العلوي & \multirow{4}{*}{ بعد الجها } \\
\hline 3.24 & 3.80 & 8 & السفلي & \\
\hline 8.02 & 11.17 & 8 & المختلط & \\
\hline 6.10 & 6.07 & 24 & المجموع & \\
\hline 0.88 & 2.75 & 8 & العلوي & \multirow{4}{*}{ بعد (V) د } \\
\hline 2.43 & 3.04 & 8 & السفلي & \\
\hline 5.96 & 12.18 & 8 & المختلط & \\
\hline 5.73 & 5.99 & 24 & المجموع & \\
\hline 1.04 & 2.02 & 8 & العلوي & \multirow{4}{*}{ بعد (· ب) د } \\
\hline 1.94 & 1.78 & 8 & السفلي & \\
\hline 2.14 & 10.55 & 8 & المختلط & \\
\hline 4.49 & 4.78 & 24 & المجموع & \\
\hline 0.46 & 0.96 & 8 & العلوي & \multirow{4}{*}{ بعد (· • د) د } \\
\hline 1.08 & 1.04 & 8 & السفلي & \\
\hline 1.63 & 8.72 & 8 & المختلط & \\
\hline 3.88 & 3.57 & 24 & المجموع & \\
\hline
\end{tabular}




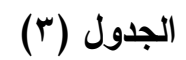

تحليل التباين لاثر تمارين القسم العلوي والسفلي

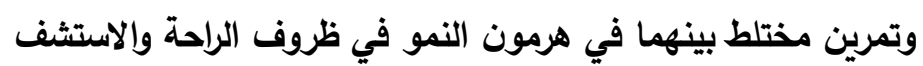

\begin{tabular}{|c|c|c|c|c|c|c|}
\hline المعنوية & $\mathbf{F}$ & المربعات & الحربة & المربعات & مصدر التباين & الاختبار \\
\hline \multirow[t]{3}{*}{$\cdot .999$} & $\cdot .001$ & $\cdot .001$ & 2 & $\cdot .001$ & بين المجاميع & \multirow{3}{*}{ الراحة } \\
\hline & & $\cdot .270$ & 21 & 5.662 & داخل المجاميع & \\
\hline & & & 23 & 5.662 & المجموع & \\
\hline \multirow[t]{3}{*}{$0.008 * *$} & 6.063 & 156.478 & 2 & 312.957 & بين المجاميع & \multirow{3}{*}{ بعد الجهر } \\
\hline & & 25.809 & 21 & 541.993 & داخل المجاميع & \\
\hline & & & 23 & 854.950 & المجموع & \\
\hline \multirow[t]{3}{*}{$0.001 * *$} & 16.375 & 230.226 & 2 & 460.452 & بين المجاميع & \multirow{3}{*}{ بعد (V) د } \\
\hline & & 14.059 & 21 & 295.244 & داخل المجاميع & \\
\hline & & & 23 & 755.695 & المجموع & \\
\hline \multirow[t]{3}{*}{$0.001 * *$} & 63.504 & 199.373 & 2 & 398.747 & بين المجاميع & \multirow{3}{*}{ بعد (Y. (Y) } \\
\hline & & 3.140 & 21 & 65.931 & داخل المجاميع & \\
\hline & & & 23 & 464.677 & المجموع & \\
\hline \multirow[t]{3}{*}{$0.001 * *$} & 118.12 & 159.239 & 2 & 318.477 & بين المجاميع & \multirow{3}{*}{ بعد (·r) } \\
\hline & & 1.348 & 21 & 28.308 & داخل المجاميع & \\
\hline & & & 23 & 346.785 & المجموع & \\
\hline
\end{tabular}

يبين الجدول (r) وجود فرق معنوي في ظروف (بعد الجهد , 0.008 , • r , , •rم) اذ بلغت قيمة المعنويـة

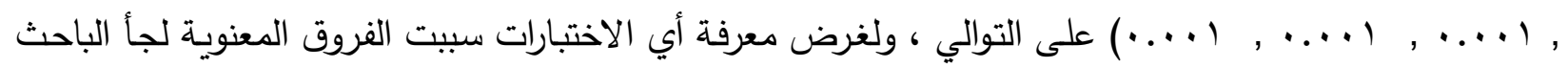
إلى استخراج قيمة أقل فرق معنوي بواسطة اختبار (Duncan) في الجدول (ع) وعلى أساس مقارنتها مـع الفروق في الأوساط الحسابية . 


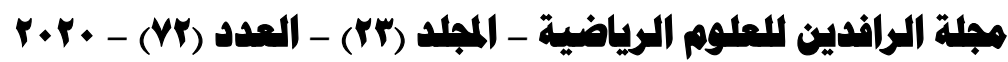

دراسة مقارنة لتأثير تمارين الاثقال والاستشفاء بين القسمين العلوي والسفلي من الجسم وتمرين مختلط بينهما في هرمون النمو

الجدول (؛ ) اختبار (Duncan) للمقارنة بين اختبارات القسم العلوي

والسفلي وتمرين مختلط بينهما في هرمون النمو في ظروف الراحة والاستثفاء

\begin{tabular}{|c|c|c|c|c|}
\hline \multicolumn{2}{|c|}{ مستوى ألفا = 0.05} & \multirow{2}{*}{ عدد افراد العينة } & \multirow{2}{*}{ 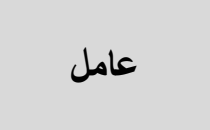 } & \multirow{2}{*}{ ظرف الاختبار } \\
\hline r & 1 & & & \\
\hline & .7463 & 8 & علوي & \multirow{4}{*}{ الراحة } \\
\hline & .07463 & 8 & سفلي & \\
\hline & 0.07463 & 8 & مختلط & \\
\hline &. .999 & & درجة المعنوية & \\
\hline & r.roro & $\wedge$ & علوي & \multirow{4}{*}{ بعد الجها } \\
\hline & r.V৭^^ & $\wedge$ & سفلي & \\
\hline $11.1 \mathrm{~V} 1 \mathrm{r}$ & & $\wedge$ & مختلط & \\
\hline \multirow[t]{3}{*}{.999} & . Arr & & درجة المعنوية & \\
\hline & 2.7531 & 8 & علوي & \multirow{4}{*}{ بعد(V) د } \\
\hline & 3.0350 & 8 & سفلي & \\
\hline 12.1825 & & 8 & مختلط & \\
\hline \multirow[t]{3}{*}{. .999} & $\cdot .882$ & & درجة المعنوية & \\
\hline & 1.7825 & 8 & علوي & \multirow{4}{*}{ بعد( • ب) د } \\
\hline & 2.0190 & 8 & سفلي & \\
\hline 10.5450 & & 8 & مختلط & \\
\hline \multirow[t]{3}{*}{. .999} & 0.792 & & درجة المعنوية & \\
\hline & 0.9556 & 8 & علوي & \multirow{4}{*}{ بعد • • (r) د } \\
\hline & 1.0375 & 8 & سفلي & \\
\hline 8.7238 & & 8 & مختلط & \\
\hline. .999 & 0.889 & & درجة المعنوية & \\
\hline
\end{tabular}

يبين لنـا الجدول (ع) نتائج اختبار (Duncan) إذ كانت نتائج ظرف (بعد الجهد) كالاتي ( لا يوجد فرق معنوي في متوسطات التمرين العلوي والسفلي, وجود فرق معنوي في متوسطات التمرين العلوي والمختلط ولصـالح التمرين المختلط, وجود فرق معنوي في متوسطات التمرين السفلي والمختلط ولصسالح التمرين المختلط). بينما اظهرت نتائج ظرف (Vد) كـالآتي (لا يوجد فرق معنوي في متوسطات التمرين العلوي والسفلي, ووجود فرق معنوي في متوسطات التمرين العلوي والمختلط ولصـالح التمـرين المختلط, ووجود فرق معنوي في متوسطات التمرين السفلي والمختلط ولصالح التمرين المختلط). بينما اظهرت نتائج ظرف (· r د) كالآتي (لا يوجد فرق معنوي في متوسطات التمرين العلوي والسفلي, وجود فرق معنوي في متوسطات التمرين العلوي والمختلط ولصسالح التمرين المختلط, ووجود فرق معنوي في متوسطات التمرين السفلي والمختلط ولصـالح التمرين المختلط). بينما اظهرت نتائج ظرف (. ب د د) كالآتي (لا يوجد فرق معنوي في متوسطات التمرين العلوي والسفلي, ووجود فرق معنوي في متوسطات التمرين العلوي 


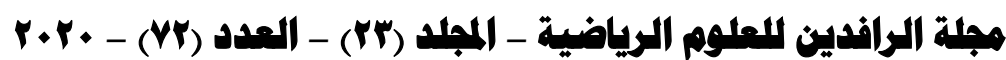

دراسة مقارنة لتأثير تمارين الاثقال والاستثفاء بين القسمين العلوي والسفلي من الجسم وتمرين مختلط بينهما في هرمون النمو

والمختلط ولصـالح التمرين المختلط, ووجود فرق معنوي في متوسطات التمرين السفلي والمختلط ولصـالح التمرين

(المختلط).

اتثقت هذه النتائج مـع دراسة (Häkkinen etal, 1998) الذي شاهد زيادة معنويـة بتركيز هرمون النمو بعد

تمرين المقاومة للقسم السفلي بشدة مرتفعة ,كما اتفقت مع ما ذكره (Godfrey etal, 2003) عند مقارنـة جلسات التدريب مـع ثابت العمل الكلي ،فإن التمرين الذي يتطلب أكبر قدر من تحلل السكر اللاهوائي سيحفز ارتفاعات هرمون النمو في مصل الدم • إذ اظهرت النتائج أن التمرين المختلط أدى إلى زيادة معنويـة في هرمون النمو مقارنة بالتمرين العلوي والسفلي , كما ذكر ان ارتفاع اللكتات لـه علاقة قويـة بارتفاع هرمون النمو ,ويبدو أن شدة التمرين فوق عتبة اللاكتات و لمدةظ (· (1) دقائق على الأقل ستؤدي إلى استثارة عظيمة لإفراز هرمون النمو ( Godfrey

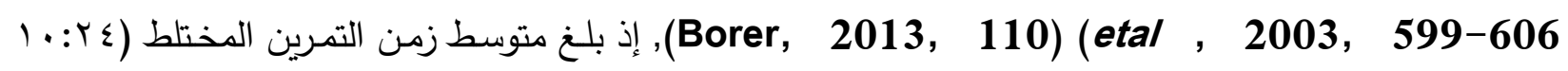
دقيقة:ثانية) وللتمرين العلوي والسفلي (r دقائق , ـ :ء دقيقة:ثانية) على التوالي. ونعزو سبب معنوية نتائج استعادة شفاء هرمون النمو إلى نوع التمرين المستخدم والذي اعتمد على اقصى تراكم

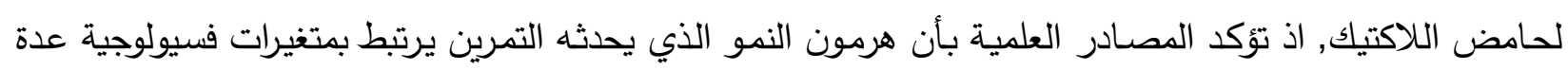
تؤثر في ارتفاعه تتضمن (التحفيز العصبي, والتحفيز المباشر للكاتيكولامين, واللاكتيك, وأكسيد النيتريك, والتغير في ئرئ التوازن الحامضـي - القاعدي) ويعد كل من اللاكتيك واكسيد النتريك من افضـل المحفزات التي تؤثر في ارتفاع هرمون النمو. ويعد حمل وتكرار التمرين المستخدم في البحث من العوامل المحددة في تتظيم إفراز هرمون النمو الذي يؤدي إلى تخليق البروتينات التي تضررت نتيجة التمرين, وإن هناك الكثير من الحوافز التي تؤدي لتخليق البروتين بسبب تمارين المقاومة مثل عامل النمو الثبيه بالأنسولين-1 (IGF-1) ومن المعلوم بأن افراز هذا العامل ينظم

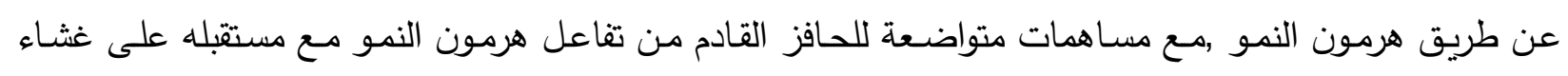

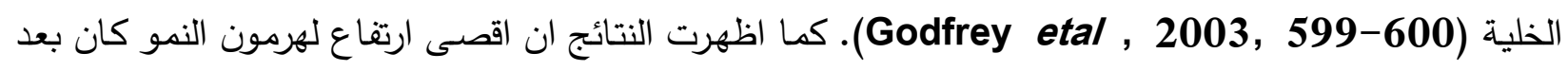

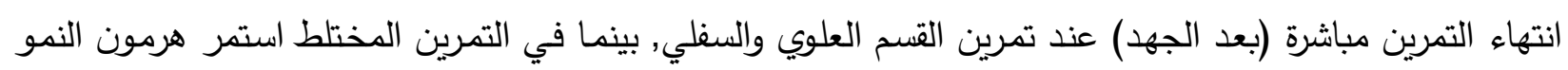
بالارتقاع بعد انتهاء التمرين ولمدة (V دقائق) , ونعزو هذا السبب إلى زمن توتر الخلايا العضلية (شدة التوتر) والذي

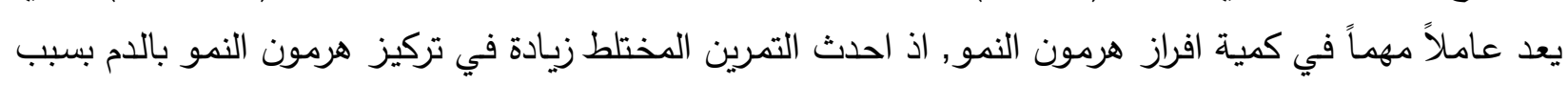

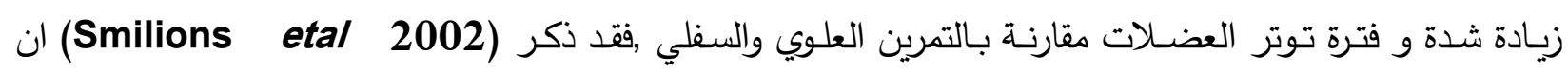
الاختلاف في شدة وزمن التوتر العضلي دليل على كمية الحمل التدريبي ودالتة على العمل الكلي للخلايا العضلية الذي يتباين بين العمليات الايضية والاجراءات الهرمونية داخل الخلايا فعندما تطبيق بروتوكول للقوة العضلية بشدة قصوى وفترة قصيرة سيؤدي إلى تتشيط الأيض اللاهوائي لفترة قصيرة وبالتالي تتشيط الآلية الخلويـة لنمو العضلة

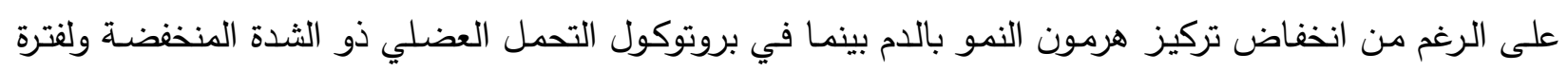
طويلـة سيؤدي إلى تتشيط عـالي للايض اللاهوائي, وكذلك استجابات هرمونيـة مرتفعـة لتنشيط العمليات المرتبطـة باستعادة ركائز الطاقة (Smilions etal, 2002, 652-653), كما ان طريقة المقاومة التي تحتوي على عدد هدئ

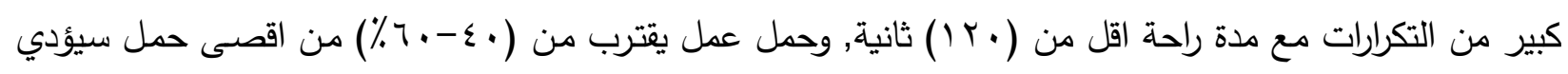

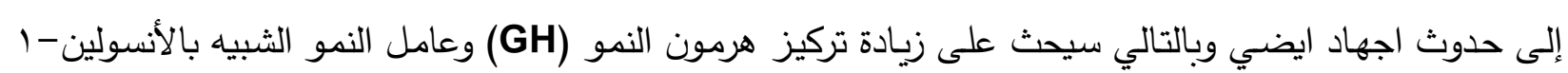

.(Migual etal, 2018, 158) (IGF-1) 


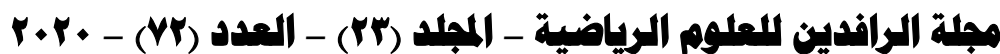

دراسة مقارنة لتأثير تمارين الاثقال والاستثفاء بين القسمين العلوي والسفلي من الجسم وتمرين مختلط بينهما في هرمون النمو ع - r عرض ومناقشة وتحليل نتائج المقارنة بين استعادة شفاء هرمون النمو بعد حمل استنفاذي بالاثقال في

القسم العلوي مع القسم السفلي وتمرين مختلط بينهما. الجدول (ه) المعالم الاحصائية للمقارنة بين استعادة شفاء هرمون النمو بعد حمل إستنفادي

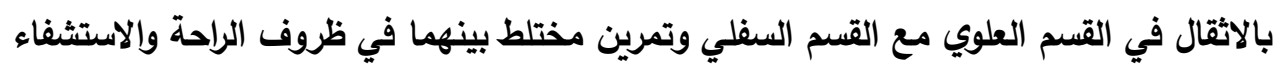

\begin{tabular}{|c|c|c|c|c|}
\hline$\varepsilon^{ \pm}$ & سنَ & علد الفراد & التمارين & المتغيرات \\
\hline 0.52 & 0.75 & $\wedge$ & راحة & \multirow{5}{*}{ العلوي } \\
\hline 1.60 & 3.25 & $\wedge$ & بعد الجهد & \\
\hline 0.88 & 2.75 & $\wedge$ & $د V$ & \\
\hline 1.04 & 2.02 & $\wedge$ & $د$ r. & \\
\hline 0.46 & 0.96 & $\wedge$ & . & \\
\hline 0.75 & 0.52 & $\wedge$ & راحة & \multirow{5}{*}{ السفلي } \\
\hline 3.80 & 3.24 & $\wedge$ & بعد الجها & \\
\hline 3.04 & 2.43 & $\wedge$ & $د V$ & \\
\hline 1.78 & 1.94 & $\wedge$ & $د$ r. & \\
\hline 1.04 & 1.08 & $\wedge$ & . & \\
\hline 0.52 & 0.75 & $\wedge$ & راحة & \multirow{5}{*}{ المختلط } \\
\hline 8.02 & 11.17 & $\wedge$ & بعد الجهد & \\
\hline 5.96 & 12.18 & $\wedge$ & $د V$ & \\
\hline 2.14 & 10.55 & $\wedge$ & r. & \\
\hline 1.63 & 8.72 & $\wedge$ & r د & \\
\hline
\end{tabular}

الجدول (؟) تحليل التباين للمقارنة بين استعادة شفاء هرمون النمو بعد

حمل إستنفادي بالاثقال في القسم العلوي مع القسم السفلي وتمرين مختط بينهما

\begin{tabular}{|c|c|c|c|c|c|c|}
\hline المعنوية & $F$ & المتوسطع & درجة & المربعات & القياس & \\
\hline $.001 * *$ & 30.777 & 50.250 & 1 & 50.250 & راحة - بعد الجها & \multirow{4}{*}{ العلوي } \\
\hline$\cdot 139$ & 2.781 & 1.990 & 1 & 1.990 & بعد الجها - V د & \\
\hline $0.009 * *$ & 39.147 & 4.322 & 1 & 4.322 & $د r \cdot-\Delta V$ & \\
\hline $.002 * *$ & 22.854 & 9.031 & 1 & 9.031 & . & \\
\hline. $.022 *$ & 8.580 & 74.542 & 1 & 74.542 & راحة - بعد الجها & \multirow{2}{*}{ السفلي } \\
\hline$\cdot .071$ & 4.530 & 4.667 & 1 & 4.667 & بعد الجها - V د & \\
\hline
\end{tabular}




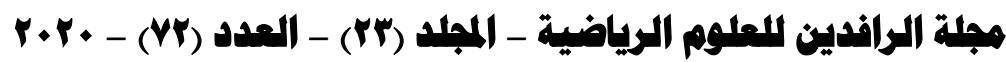

دراسة مقارنة لتأثير تمارين الاثقال والاستثفاء بين القسمين العلوي والسفلي من الجسم وتمرين مختلط بينهما في هرمون النمو

\begin{tabular}{|c|c|c|c|c|c|c|}
\hline. $.002 * *$ & 23.539 & 12.550 & 1 & 12.550 & $د r \cdot-د V$ & \\
\hline$\cdot .060$ & 5.015 & 4.440 & 1 & 4.440 & . & \\
\hline. $.006 * *$ & 14.850 & 869.445 & 1 & 869.445 & راحة - بعد الجهد & \multirow{4}{*}{ المختلط } \\
\hline$\cdot .268$ & 1.446 & 8.181 & 1 & 8.181 & بعد الجها - V د & \\
\hline$\cdot .374$ & .901 & 21.451 & 1 & 21.451 & $د r \cdot-\Delta V$ & \\
\hline. $.015^{*}$ & 10.411 & 26.536 & 1 & 26.536 & . & \\
\hline
\end{tabular}

يوضح الجدول (7) نتائج تحليل التباين في استعادة شفاء هرمون النمو بعد حمل استتفاذي بالأثقال في القسم

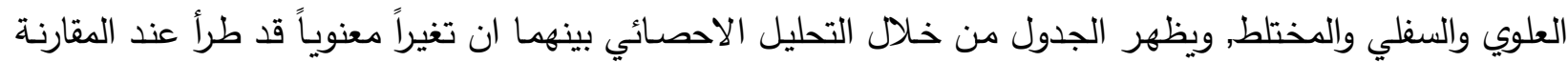

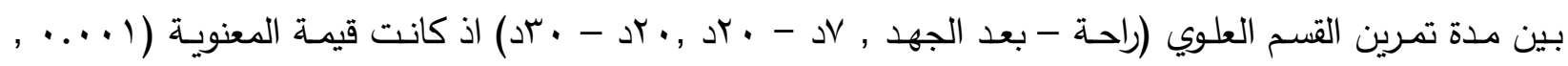

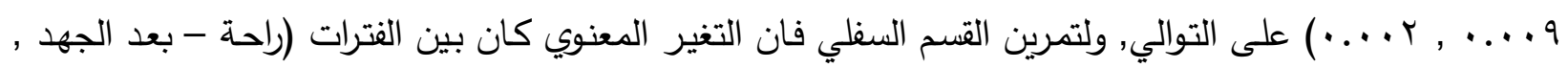

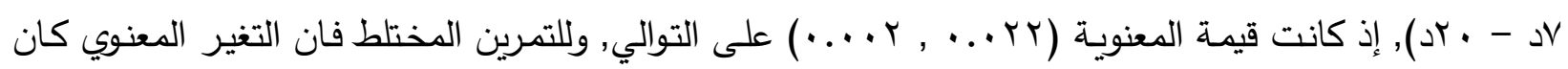

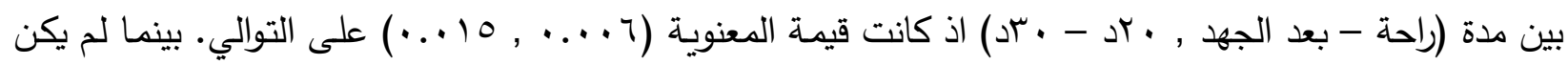

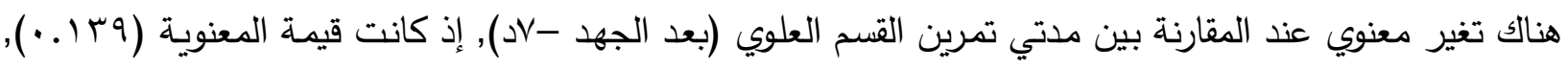

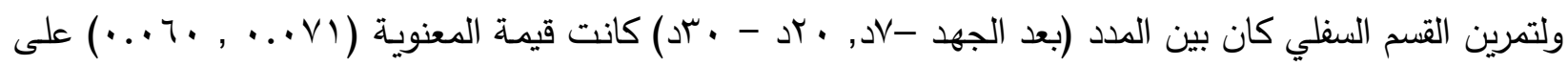

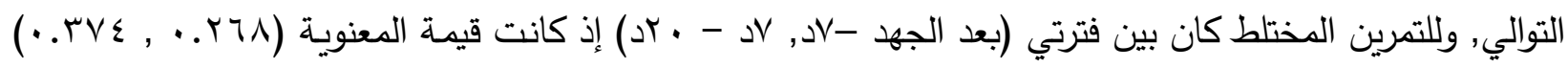
على التوالي.

ويعزو الباحث هذا الارتفـاع إلى الجهد البـني لتمـارين القسـم العلـوي والسـلي والمختلط ، اذ احدث الحمـل الاستفاذي لتمارين الأثقال في القسم العلوي والمختلط ارتفاعاً معنوياً في قسم من فترات استعادة شفاء هرمون النمو واتفقت هذه النتيجة مع ما توصلت إليه دراسة (HaÈkkinen etal 1998) إلى أن الجهد البدني للتمارين الثابتة

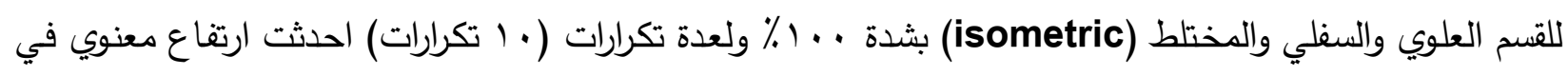

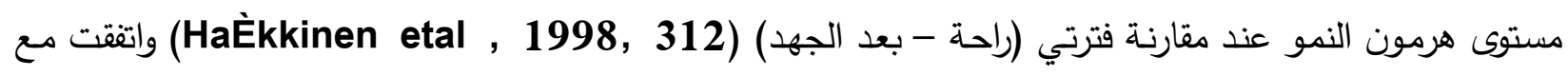
نتائج (Kraemer etal 1993 الذي شاهد ارتفاع معنوي كبير في أوقات الاستشفاء (بعد الجهد ,0 , 10 ) مقارنة بقيم الراحة بعد الانتهاء من تمرين بدني شديد بالأثقال, وكذلك كان هناك تغير معنوي كبير في قيم استعادة الشفاء

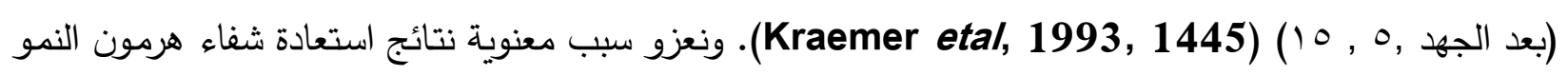
إلى نوع التمرين المستخدم والذي اعتمد على اقصى تراكم لحامض اللكتات, اذ تؤكد المصادر العلمية بأن زيادة تركيز

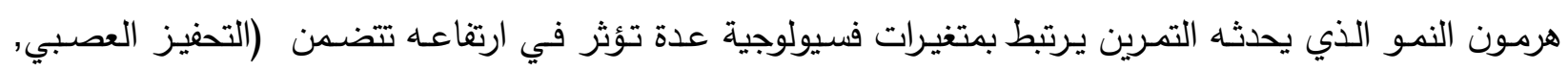
والتحفيز المباشر للكاتيكولامين, واللاكتيك, وأكسيد النيتريك, والتغير في التوازن الحامضي - القاعدي) ويعتبر كل من فن فئن اللاكتيك واكسيد النتريك من افضل المحفزات التي تؤثر في ارتفاع هرمون النمو, إذ ذكر (Godfrey etal 2003)

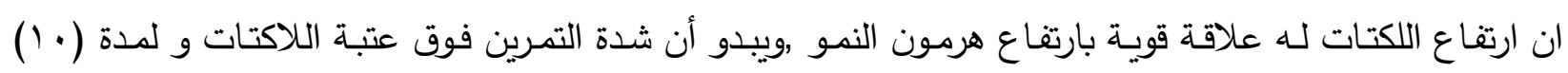

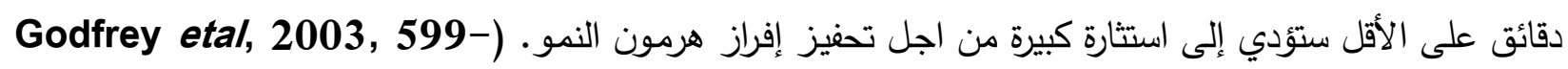
600). ويعتبر حمل وتكرار التمرين المستخدم في البحث من العوامل المحددة في تتظيم إفراز هرمون النمو, والذي يؤدي إلى تخليق البروتينات التي تضررت نتيجة التمرين هذا, فقد ذكر (Godfrey etal 2003) إن هناك الكثير هنري 
دراسة مقارنة لتأثير تمارين الاثقال والاستثفاء بين القسمين العلوي والسفلي من الجسم وتمرين مختلط بينهما في هرمون النمو

من الحوافز التي تؤدي لتخليق البروتين بسبب تمارين المقاومـة مثل عامل النمو الثبيه بالأنسولين - (IGF-1)

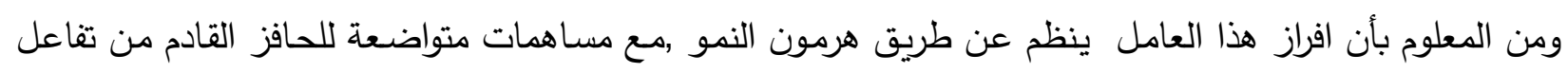
هرمون النمو مع مستقبله على غشاء الخلية (Godfrey etal, 2003, 600).و تعتبر فترة الراحة القصيرة بين

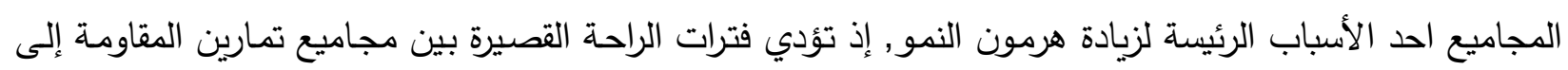
زيادة معنوية في هرمونات الابنفرين والنورابنفرين والكرتزول وهرمون النمو وهذه الهرمونات تلعب دور في الاستجابة

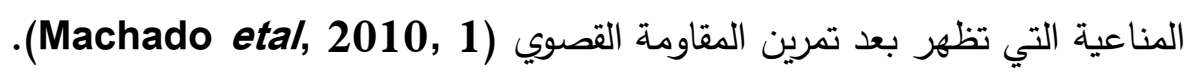
ه-الاستنتاجات والتوصيات - 1 - 1 الاستنتاجات ا. ـ احدث الحمل الاستنفاذي لمتغير هرمون النمو فروق معنوية ما بين القسم العلوي والسفلي والمختلط في ظروف الاستثفاء (بعد الجهد, Vد, · rد, • بد). r. احدث الحمل الاستنفاذي لتمارين الاثقال لمتغير هرمون النمو فروق معنوية على فترات الاستثفاء للقسمي

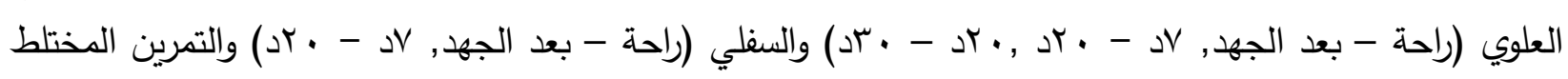

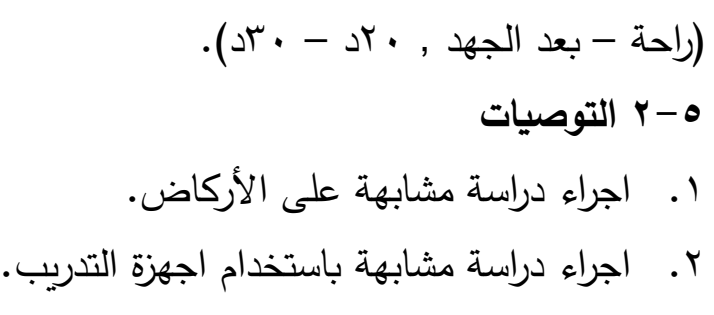
r. استخدام المدربين فترات الاستشفاء في اثناء وضعهم البرامج التدربية لتمارين القوة. ع. ـ يجب على المدربين الأخذ بالحسبان الفترات الزمنية لاستثفاء اللكتات عند المنافسات التي تعتمد على النظام الاكتاتي كنظام سائد. ه. يجب على المدربين العناية بفترة الراحة بين الوحدات التدريبية عند التدربب باستخدام الاثقال للتمارين التي تعتمد على النظام اللاكتاتي 7. اجراء المزيد من الدراسات حول المقارنة بين القسم العلوي والسفلي والخلط بينهما وتأثيرها في الاستجابة الهرمونية لهرمون (التستوستيرون, الكورتزول). -

1. Amitrano Robert J. \& Tortora Gerard J (2007): Laboratory Exercises in Anatomy \& Physiology with Cat Dissections, 8th, Thomson Brooks/Cole, USA .

2. Borer, Katarina T (2013) Advanced Exercise Endocrinology, Human Kinetics, USA.

3. Cittadini , Antonio \&. Douglas, Pamela S (2001) The Cellular \& Molecular Basis For Growth Hormone Action On The Heart, Springer Science, USA.

4. Foss ,merle L . Keteyian ,Steven J (1998): Fox's Physiological Basis for Exercise \& Sport, Mc Graw-Hill ,USA.

5. Giovanni, Lombardi \& Colao, Annamaria S (2001) Physiological Effects Of Growth Hormoneon The Heart, Springer Science, USA.

6. Godfrey, Richard J. Madgwick ,Zahra . Whyte ,Gregory P (2003) The ExerciseInduced Growth Hormone Response in Athletes, Sports Med, UK. 
7. HaÈkkinen ,K. Pakarinen ,A . Newton ,R.U. Kraemer ,W.J. (1998) Acute hormone responses to heavy resistance lower and upper extremity exercise in young versus old men , Eur J Appl Physiol, Finland.

8. Hymer, Wesley c. Grindeland, Richard e. Nindl Bradley c. Kraemer, William j. (2005): The Endocrine System In Sports and Exercise, black well , USA.

9. Kraemer, W.J. \& Other (1993) Changes in hormonal concentrations after different heavy-resistance exercise protocols in women, Journal of Applied Physiology, Vol. (75) No. (2), USA.

10.Kraemer, W.J. Marchitelli, L. Gordon, S.E. et al. (1990) Hormonal and growth factor responses to heavy resistance exercise protocols, Journal of Applied Physiology, Vol. (69) No. (4), USA.

11.Machado, Marco. \& Others (2010) Effect Of Varyingrest Intervals Between Sets Of Assistance Exercises On Creatine Kinase and Lactate Dehydrogenase Responses, Journal of Strength and Conditioning Research.

12.Madarame, Haruhiko. Sasaki, K. Ishii, N (2010) Endocrine responses to upper- and lower-limb resistance exercises with blood flow restriction, Acta Physiologica Hungarica.

13.McArdle, William D. Katch, Frank I. Katch , Victor L. (2010): Exercise physiology : nutrition, energy, and human performance, 7th ed, Lippincott Williams and Wilkins ,USA.

14.Miguel, Henrique \& others (2018) Analysis Of Acute Responses Of Lactacidemy Indifferent Strength Training Methods In Trained Men, European Journal of Physical Education and Sport Science, Vol. (4) Issue (1), Brasil.

15.Rahimi, Rahman. Ghaderi, Mohammad. Boroujerdi, Saeed Sadeghi (2010) Effect Of Very Short Rest Periods On Hormonal Responses To Resistance Exercise In Men, Journal Of Strength and Conditioning Research, Iran.

16.Rizzo ,Donald C (2010) Fundamentals of Anatomy and Physiology , Third Edution, Cengage Learning, USA.

17.Smilions, Ilias. \& Other (2002) Hormonal Responses after Various Resistance Exercise Protocols, American College of Sports Medicine, USA. 